sadness was that Dr George had left. It was rumoured that he had given the "wrong medicine" and that he was going to a community further out into the desert, where his prestige was still strong. When we saw him leaving the initiations he was happily waving from the back of a crowded truck on his way to Jigalong, a four day drive away, and we wondered if he would ever come back.

Our return confirmed my earlier impressions. I found the Aborigines a gifted and lovable people who are making a brave attempt to adjust to our society. We must remember that we are asking them to achieve in 200 years a level of sophistication that has taken us
2000. Had I a wish to be granted it would be that they would suddenly develop the confidence to take the responsibility for their future into their own hands and that we would be given the patience necessary while they are developing; this will be an appreciably longer time than everyone expects.

1 Royal College of Ophthalmologists. National trachoma and eye health programme. Sydney: RCO, 1980.

2 Dawson VM, Coelen RJ, Murphy S, Graham D, Dyer H, Sunderman J. Microbiology of chronic otitis media with effusion among Australian Aboriginal children: role of Chlamydia trachomatis. Aboriginal Health Bulletin 1987;8:5

3 Beck EJ. The enigma of Aboriginal health. Canberra: Australian Institution of Aboriginal Studies, 1985.

\title{
Health in rural south India: new approaches
}

\author{
Patricia Day Bidinger
}

"Health for all in the year 2000" is a phrase often repeated in medical circles. Countless participants at conferences have debated how to achieve this objective. One of the main problems has been how to translate this broad objective into programmes targeted at responding effectively to local health care needs. The Institute for Rural Health Studies in Hyderabad, south India, was established to carry out research on the nature and causes of rural health problems. Through its research on specific problems and their causes, as well as through its pilot programmes in health care delivery, the institute is turning the broad objective of health for all into specific recommendations for rural village health programmes and also for government policy makers.

The institute was founded in 1981 by two women scientists concerned about the lack of applied, interdisciplinary research in health and nutrition problems common in rural areas of the Indian state of Andhra Pradesh. Previous work in rural villages in the states of Maharashtra and Andhra Pradesh had indicated the complex and interdisciplinary nature of health and health related problems. Rural primary health centres were failing to provide even a minimal level of health care to anyone outside the immediate area of the centre itself. Centres were few and far between; the greater the distance from a city or town, the less likely was a primary health centre, and if one existed it was likely to lack a doctor or medical supplies, or both. Cold boxes

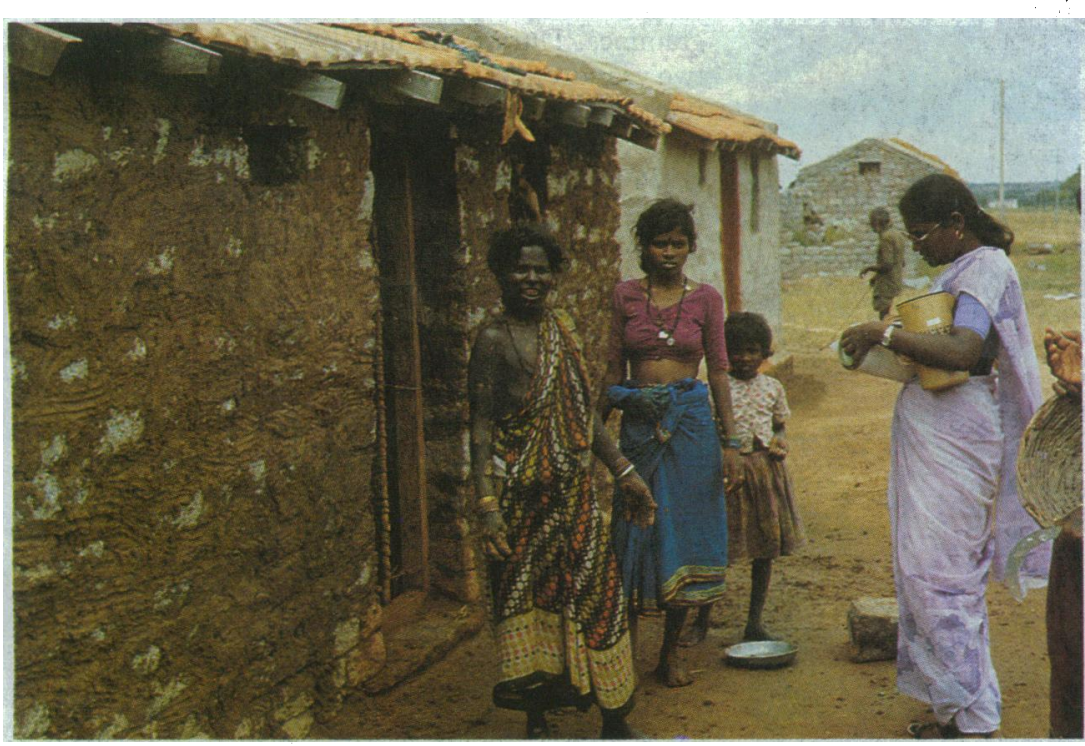

Data gathering $-P$ Babu, the institute's research associate, visits villagers

Studies, 8-2-120/86/5 Road 2, Hyderabad 500 034, acting director

BrMed f 1990;301:1441-3 for vaccines were usually "warm boxes," and vaccinations never reached villages at any distance from towns; meanwhile, officials complained about the poor response to their vaccination programmes. Polio, diphtheria, and whooping cough were still common village ailments.

Apart from villagers themselves, few people seemed to know what specific problems faced rural villagers during the year. Few professionals had attempted to examine the relation between agriculture, economics, and health or realised that "health" problems might not be just medical problems. For example, the lack of transportation to a distant medical facility is an impediment to good health. Thus, the institute's early studies focused on agricultural and socioeconomic determinants of nutrition and health state, and later ones have been devoted to evaluating ways to improve health care delivery.

\section{Seasonal fluctuations in food supplies}

One of the institute's first major studies examined the relation of seasonal fluctuations in the production of food in a village to individual food consumption and health in families with young children. ${ }^{1}$ Policy emphasised the need to target food at poorer villagers, especially children, during the "lean" seasons, but the research showed that food supplies were available throughout the year and that consumption of food was not seasonal. A small segment of villagers remained chronically underfed throughout the year, generally because of social causes - for example, a widow or elderly couple living alone with little support. The equalisation of food supplies could be traced to the availability of easy credit to farmers through the state bank's lending programme. Farmers had used the credit to augment irrigation (sinking new wells and deepening old ones), which enabled them to increase cropping intensity and led to more work, a greater demand for labour, and hence better conditions for labourers. Farmers expressed fears that they would be short of labour and began to offer labourers both higher wages and access to small loans, primarily paddy rice for consumption during the slack seasons. The result was a sharp decrease in the incidence of undernutrition among children and adults and no evidence of seasonal variation in either anthropometric indices or food consumption.

Presented with these unexpected results, bank officials said that it was the first piece of statistical evidence to show the impact of their credit programme on health and nutrition. That programme has now 
been expanded and extended throughout the state, and will obviously have a great impact on food consumption, health, and the general welfare of the poor sections of village society.

\section{Water supplies}

The provision of clean water supplies has long been an important objective of both international and local development authorities. Hand dug, open wells have traditionally been the main source of water in villages throughout the developing world. Samples of water from such village wells in Maharashtra and Andhra regularly show high levels of contamination with coliform bacteria (usually $\geqslant 2400$ per $100 \mathrm{ml}$ ). Escherichia coli $\mathrm{I}$, indicative of faecal contamination, is always found. Aware of the seriousness of the problem, the Indian government has been carrying out a massive programme to provide protected water suppliessealed bore wells - in every village. The institute's researchers sampled water from these newer water sources and found it to be subject to several sources of contamination: the water itself can become contaminated as a result of children putting their hands inside the taps and household water supplies from home storage containers through failure to clean properly and cover the containers and to keep hands from touching the water when removing it from the container. Thus, even protected water supplies do not guarantee clean water for vulnerable groups such as young children.

This raised the question of whether it was necessary to give breast fed babies an external source of water if that very water was a possible source of diarrhoeal diseases. The institute's researchers collected urine samples from healthy, exclusively breast fed babies under 10 months to determine whether there was a need for an external source of water. ${ }^{2}$ The study was carried out in April and May, when water requirements would be expected to be at their maximum: daily temperatures at this time frequently rise to $40^{\circ} \mathrm{C}$ or

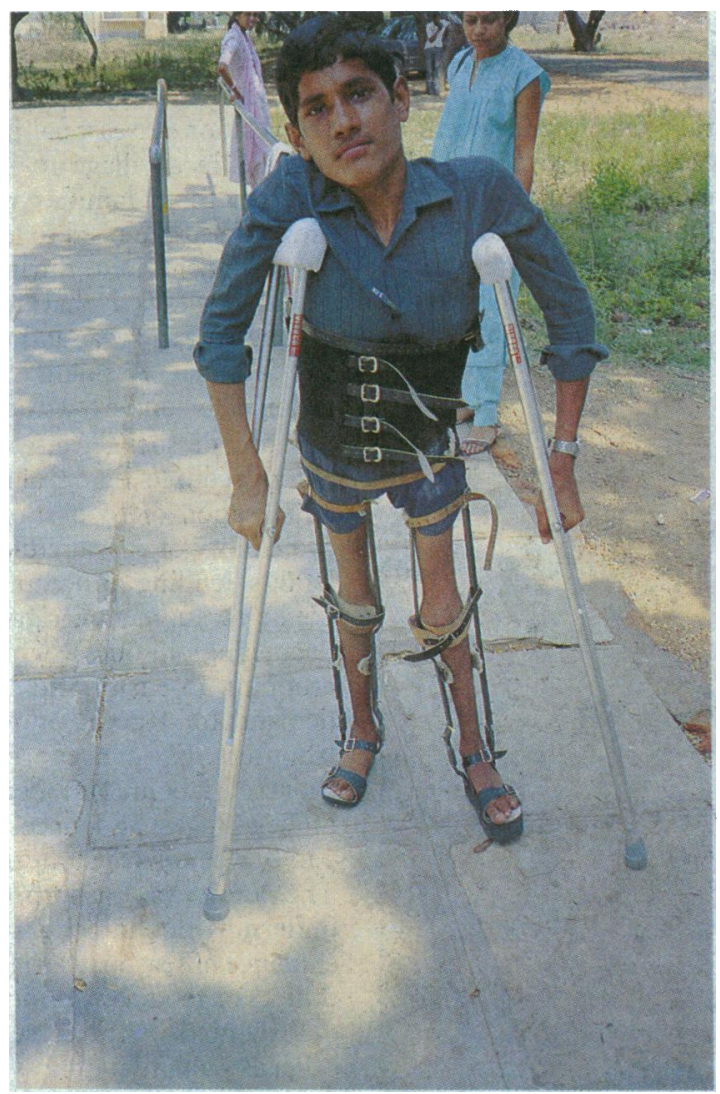

Patients needing complex treatment are taken to see specialists in larger centres. Raju, who had polio, is now a trained health worker more, with relative humidity as low as $10 \%$. Specific gravity was chosen as a proxy for osmolarity to determine whether the babies were dehydrated. There was no evidence of dehydration with exclusive breast feeding. We concluded that exclusively breast feeding infants for the first four to six months is a reasonable public health recommendation and is imperative in areas where contaminated drinking water may contribute to infant morbidity, particularly diarrhoeal disease.

\section{Intestinal parasites}

Intestinal parasites are endemic and widespread in rural Indian villages: sanitation is poor, and latrines of any sort are rarely found. Villagers use what is commonly referred to as the defecation field at the edge of the village, and young children use the area outside the family dwelling. This clearly results in a high probability of spread of intestinal parasites.

The institute began a collaborative project several years ago with a British parasitologist to identify species present in villagers living in both irrigated and non-irrigated villages, the age they became infected, and the social and biological determinants of the parasitic infection. Nearly 1500 stool samples were collected from an age stratified sample, beginning with infants, over a two and a half year period. Although the study has yet to be completed, some interesting preliminary results are known. More than 10 different parasites have been identified; most species were expected, including ascaris, hookworm, giardia, and two species of hymenolepsis. An unexpected finding was the presence of schistosoma, ${ }^{3}$ which has been identified in only two other locations in India, both of which are hundreds of miles from the study villages.

Staff of the institute have collected water samples, fingernail scrapings, and soil samples from the same families in an effort to learn more about possible determinants, and an extensive questionnaire about knowledge, attitudes, and practices was administered to the same families. With the knowledge gained from this work the institute hopes to identify major sources of infection and to recommend public health measures, including an education campaign, to reduce the level of parasitic infection.

\section{Drought}

In semiarid India drought is common. It is both a human and a political problem; more knowledge of the consequences of drought on health and welfare is needed to fashion more effective adjustment programmes. During the mid-1980s there was a serious two year drought in one of the areas in which the institute carries out research. The institute had extensive data on families during normal agricultural years (1976-9 and 1982-3) and could assess the consequences of the drought by direct comparison of this and new data obtained by following the same 81 families, who represented $20 \%$ of the 1986 population in an irrigated village typical of thousands in south India. ${ }^{4}$

Morbidity, anthropometric indices, food consumption, physical health, economic transactions, food prices and availability, crop production, and labour force participation were compared before and during two years of drought. Although this was the harshest drought in living memory, the stability of food grain prices and the widespread availability of credit permitted the villagers largely to maintain the consumption patterns of normal years. There was, however, a great deal of unemployment among the labourers, especially the women, which could have been averted by a timely public works scheme. The greatest constraint to the villagers was simply the lack of water, 


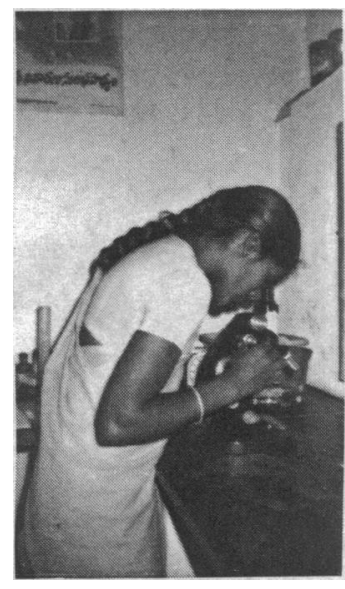

Chandrakala, the institute's health worker, checking a blood smear for malaria. Laboratories in village clinics are designed to run without electricity and to use equipment and supplies available locally potable or otherwise, due both to open wells drying up and a shortage of electricity with which to run the pump for the protected water supply. (Electricity is derived mainly from hydroelectric sources, which were severely affected by the drought.) The scarcity of readily available clean water led to an appreciable increase in related illness-primarily diarrhoeal diseases, eye infections and scabies - especially during the second year of the drought. For policy makers the implications are obvious; providing public works projects to counter unemployment, ensuring stability of food grain prices, and improving water supplies by maintaining the supply of electricity and providing deeper bore wells serving protected water supplies.

\section{Health care delivery}

Most of the health problems faced by Indian villagers are not very different from those found in temperate areas. A rural clinic can quite easily resemble a British surgery as patients with influenza, common colds, and simple injuries appear for treatment. What is different, apart from the presence of certain tropical diseases and those diseases now rare in Britain owing to effective vaccination programmes, is that patients appear in the late stages of disease. Good primary health care in rural areas is generally available only in larger market towns rather than in agricultural villages. It is also expensive: at least a day's wages are lost in seeking health care, not to mention the cost of bus fare, food while out of the village, and, finally, the doctor's fees and the medicine that is inevitably prescribed. The health care provided in market towns is invariably substandard as only the most poorly trained doctors set up such practices. The most talented Indian doctors stay in urban areas, where they can be assured of medical facilities and education for their children. In addition, "compounders" (traditional chemists) and charlatans abound-there is no legal control on anyone calling themselves a doctor.

In an effort to bring basic health care back to villages, the institute initiated a pilot study of the feasibility of village clinics with small laboratories. These are run on a daily basis by one or two trained villagers and supervised by trained, urban based, paramedics, who spend one to two weeks a month in the village. The clinics include a laboratory because tuberculosis, malaria, and anaemia-all common problems in rural areas - are often undetected. Laboratories are found only in district towns and it can take half a day to reach one, so the diagnosis of such conditions is almost never confirmed by laboratory test results. Each of the tests - for example, sputum tests for tuberculosis bacilli, blood tests for malarial parasites and haemoglobin levels, and routine urine analysis for sugar, protein, bilirubin, pus, and epithelial cells - can be carried out by trained villagers.

The young villagers with the equivalent of $\mathrm{O}$ levels who were selected for training proved to be quick and attentive pupils. The first clinic and laboratory was a small hut renovated by villagers. The laboratory was designed to work without electricity (a scarce commodity under the best of circumstances), and uses a monocular microscope, hand cranked centrifuge, and simple staining methods; all equipment and chemicals are locally available in the state capital of Hyderabad. Working with the book Where There Is No Doctor, ${ }^{5}$ the clinic workers have been taught to treat simple conditions (malaria, anaemia, etc) and to hold for examination by a senior person the patients with more complex conditions such as tuberculosis. They have been taught to check the neighbours and friends of patients newly diagnosed as having tuberculosis.

The simple clinic also serves as a referral centre; trained paramedics take patients with more complex conditions, such as those needing cardiac surgery or reconstruction after polio, to see specialists in the nearest large city. The first of these village medical facilities, set up in February 1988, now draws its patients from 25 villages over a wide area. This is due to two factors: the villagers believe that, they can get adequate care without having to leave the area, and if they must leave it they are taken to a competent medical person and looked after by institute staff.

The health secretary to the government of Andhra Pradesh (a state of 60 million people) has asked the Institute for Rural Health Studies to set up an identical facility in its model health area so that it can evaluate the effectiveness of such a facility. The institute itself is in the process of preparing a simple manual on how to set up and run "barefoot" clinics with laboratories; this will be published in both English and Telugu, the state language. Rural village clinics have been shown to be a cost effective way of providing health care and thus assuring that health for all is not just rhetoric but reality for rural people.

\section{Future projects}

The simple clinic with its basic laboratory is not offered as a panacea for all rural areas. Many villages in the state are located in isolated and remote areas where it would not be practical or cost effective to establish village based clinics. For such areas the institute is experimenting with a pilot project centring on a medical van (made in India) capable of travelling on back roads. It will provide services similar to those of the village clinics and will regularly visit as many villages as can be covered in a two week period. In addition, it will provide appropriate health education. The van will be staffed with a driver cum health educator and two paramedics in charge of the clinic and laboratory work. Vaccinations and antenatal education and care, as well as many other medical problems, will be priorities for this new project. The two year pilot scheme will examine the ability and cost effectiveness of the mobile unit to bring health care to remote areas and the willingness of villagers to use it.

To assist with training staff paramedics the institute has been fortunate to recruit a volunteèr general practitioner from London for six months through Action Health 2000 , a voluntary health recruitment service based in Cambridge. The institute hopes she will be followed by others who wish to make "health for all" a reality in rural regions of peninsular India.

1 Bidinger PD, Nag B, Babu P. Nutritional and health consequences of seasonal fluctuations in household food availability. Food and Nutrition Bulletin 1986;8:36-80.

2 Almroth S, Bidinger PD. No need for water supplementation for exclusively breast-fed infants under hot and arid conditions. Trans $R$ Soc Trop Med 1990;84:602-4.

3 Bidinger PD, Crompton D. A possible focus of schistosomiasis in Andhra Pradesh, India. Trans $R$ Soc Trop Med 1989;83:526.

4 Bidinger PD, Walker TS, Sarkar B, Ram Murthy A, Babu P. Economic, health, and nutritional consequences of the mid-80's drought on a tank irrigated, Deccan village in south India. Economic Program, Patancheru, India: International Crops Research Institute for the Semi-Arid Tropics, 1990. (Progress report 98.)

5 Werner D. Where there is no doctor. London: Macmillan, 1979.

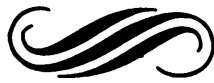

